of the earlier theorems are not referred to their sources, but to later proofs of them given in works supposed to be more accessible.

The writing and proofreading have been done with great care; apart from a few trivial errors in orthography, the only error is the reference to G. Kantor, footnote on page 131, instead of S. Kantor.

This book will be welcomed by workers in algebraic geometry; it competently fills a gap in the preparatory literature.

\title{
VIRGIL SNYDER
}

Modern Science, A Study of Physical Science in the World Today. By Hyman Levy. New York, Knopf, 1939. 736 pp. 160 illustrations.

Professor Levy's ability to present general relationships and abstractions in an interesting simple way has been commended by reviewers of his previous recent book "A Philosophy for a Modern Man." This faculty is again evident in his analysis and evaluation of social and intellectual forces in the development of physical science.

Part I of the book deals with the background of social life within which science has developed as one among many "channels" of human energy. In an interesting discussion Professor Levy contends that the work of men like Newton was largely a consequence of commercial and other social factors rather than a spontaneous intellectual activity.

Part II is concerned with the nature, methods and unity of science. Considerable stress is laid on the common occurrence of sequences of phases separated by discontinuities in physical processes. Many usually overlooked examples of these phases are given.

Parts III, IV and V deal with mathematical symbols and physical (theoretical) models. Some general algebraic and geometrical concepts are discussed. The idea of limits is presented in a remarkably concrete way. The rigor is surprisingly good for a popular discussion, but there are some undesirable implications, for example, termwise differentiability of infinite series is accepted without question. An instructive treatment of mass, momentum, impulse and energy is given. Aeronautical science is used to illustrate the unity of theory and experiment. The development of non-euclidean geometries is used to illustrate how science can "shake off the past."

Part VI is rather discursive in its discussion of astronomy, geology, atomic theory and relativity. The treatment of mountain building does not include the more modern theories of Joly and others.

Part VII on the "Age of Light" uses the history of methods of illumination and their social consequences to illustrate the depend- 
ence of various branches of science and human activity on one another.

While the reviewer can recommend this book as interesting, clear and stimulating for the moderately well informed reader, he feels that it is unnecessarily long due to redundance of examples, and that its lack of references is an unfortunate weakness.

J. K. L. MACDonald

Punktreihengeometrie. By E. A. Weiss. Leipzig and Berlin, Teubner, 1939. $8+232 \mathrm{pp}$.

The purpose of this book is to serve as an introduction to the projective geometry of higher dimensional spaces. The author adopts the point of view of Reye in regarding such space as the map space of various three-dimensional configurations and he thereby succeeds in bringing together a large variety of topics.

After a brief recapitulation of the elementary geometry of the line, the author introduces the concept of a (linear) point range (punktreihe) on a line obtained by equating to zero a bilinear form in variables $\left(\xi_{1}, \xi_{2}\right)$ and $\left(\tau_{1}, \tau_{2}\right)$, which he writes using the Clebsch-Arnold symbolic notation as $(\gamma \xi)(\mu \tau)=0$. He interprets $\left(\tau_{1}, \tau_{2}\right)$ as a parametrization of the points $\left(\xi_{1}, \xi_{2}\right)$ of the line, and he subsequently defines a point range more generally as a "one-dimensional rational manifold provided with a definite parametrization." By means of the coefficients $\gamma_{i} \mu_{j}$ linear point ranges on the line can be put in 1-1 correspondence with the points of projective 3 -space; singular ranges map into a ruled quadric, pencils and bundles of ranges into lines and planes. From the properties of singular ranges the author deduces the elementary properties of the quadric.

The two main chapters of the book deal with point ranges (and their duals) in two and three dimensions. By using symbolic notation, the Clebsch correspondence principle, and similar devices, the author derives easily such fundamental results as the harmonic properties of a quadrilateral, the projective generation of a conic, and the polar theory in the plane. Further properties of a conic follow by considering it as a point range of the second order defined analytically by $(u m)(\gamma \tau)^{2}=0$. Pascal's configurations are obtained by mapping binary quadratic forms on the points of a plane.

Linear point ranges in the plane can be mapped on $R_{5}$, projective space of five dimensions, and singular ranges correspond to a Segre manifold of three dimensions and of order 3 . The singular ranges of a pencil or bundle will map into rational cubic curves and surfaces.

The third chapter deals with geometry in $R_{3}$ and the development 